\title{
Proteomics Analysis of the Regulatory Role of Rpf/DSF Cell-to-Cell Signaling System in the Virulence of Xanthomonas campestris
}

\author{
Aileen O'Connell, ${ }^{1}$ Shi-Qi An, ${ }^{2}$ Yvonne McCarthy, ${ }^{1}$ Fabian Schulte, ${ }^{1}$ Karsten Niehaus, ${ }^{3}$ Yong-Qiang He, ${ }^{4}$ \\ Ji-Liang Tang, ${ }^{4}$ Robert P. Ryan, ${ }^{2}$ and J. Maxwell Dow ${ }^{1}$ \\ ${ }^{1}$ Department of Microbiology, Biosciences Institute, University College Cork, Cork, Ireland; ${ }^{2}$ Division of Molecular Microbiology, \\ College of Life Sciences, University of Dundee, Dundee, U.K.; ${ }^{3}$ Department of Proteome and Metabolome Research, Faculty \\ of Biology, Bielefeld University, Bielefeld, Germany; ${ }^{4}$ State Key Laboratory for Conservation and Utilization of Subtropical \\ Agro-bioresources, and College of Life Science and Technology, Guangxi University, Nanning, People's Republic of China
}

Submitted 29 May 2013. Accepted 27 June 2013.

The black rot pathogen Xanthomonas campestris utilizes molecules of the diffusible signal factor (DSF) family as signals to regulate diverse processes contributing to virulence. DSF signal synthesis and transduction requires proteins encoded by the $r p f$ gene cluster. RpfF catalyzes DSF synthesis, whereas the RpfCG two-component system links the perception of DSF to alteration in the level of the second messenger cyclic di-GMP. As this nucleotide can exert a regulatory influence at the post-transcriptional and posttranslational levels, we have used comparative proteomics to identify Rpf-regulated processes in $X$. campestris that may not be revealed by transcriptomics. The abundance of a number of proteins was altered in $r p f F, r p f C$, or $r p f G$ mutants compared with the wild type. These proteins belonged to several functional categories, including biosynthesis and intermediary metabolism, regulation, oxidative stress or antibiotic resistance, and DNA replication. For many of these proteins, the alteration in abundance was not associated with alteration in transcript level. A directed mutational analysis allowed us to describe a number of new virulence factors among these proteins, including elongation factor $P$ and a putative outer membrane protein, which are both widely conserved in bacteria.

Many plant-pathogenic bacteria use cell-to-cell communication or quorum-sensing (QS) mediated by diffusible signal molecules to regulate diverse processes contributing to virulence (Von Bodman et al. 2003). Plant-pathogenic xanthomonads, which include the black rot pathogen Xanthomonas campestris pv. campestris, utilize cis-unsaturated fatty acids of the diffusible signal factor (DSF) family as signal molecules (Ryan and Dow 2011). DSF signal synthesis and transduction in $X$. campestris pv. campestris requires proteins encoded by the $r p f$ gene cluster. RpfF catalyzes DSF synthesis, whereas the RpfCG two-component system links the perception of DSF by the sensor RpfC to alteration in the level of the second messenger, cyclic di-GMP, by RpfG, which is an HD-GYP domain

Corresponding author: J. M. Dow; E-mail: m.dow@ucc.ie

* The $e$-Xtra logo stands for "electronic extra" and indicates that four supplementary tables and two supplementary figures are published online.

C 2013 The American Phytopathological Society cyclic di-GMP phosphodiesterase (Barber et al. 1997; Ryan et al. 2006; Slater et al. 2000).

Analysis of the role of the Rpf/DSF system in a number of different xanthomonads using transcriptomics has revealed the scope of DSF regulation but has also indicated added complexity in the regulatory system (An et al. 2013; Chatterjee et al. 2008; Guo et al. 2012; He et al. 2006; Vorhölter 2013; Wang et al. 2012). The outcomes of these experiments suggest that RpfC can recognize other environmental signals in addition to DSF and point to the possibility of the existence of other regulators that interact with RpfC and alternative mechanisms for DSF perception. Furthermore, the findings suggest that RpfG may interact with further sensors to exert its regulatory function.

These transcriptional analyses have offered substantial insights into the regulatory influence of the Rpf/DSF system but do not address the possibilities of post-transcriptional and post-translational regulation. This may be of importance for the Rpf/DSF system, since cyclic di-GMP can exert a regulatory influence not only at the transcriptional level but, also, post-transcriptionally and post-translationally (Hengge 2009; Römling et al. 2013). This suggests that both transcriptomic and proteomic approaches are required to gain a fuller understanding of the regulatory actions of Rpf/DSF system and of the individual proteins.

We have recently described the use of RNA-Seq and directed mutagenesis to identify Rpf-regulated functions and virulence factors in X. campestris pv. campestris (An et al. 2013). Here, we describe the outcome of a parallel set of experiments in which proteomics was deployed to examine Rpf-regulated processes in bacteria from the same growth conditions. The findings indicate an even broader regulatory influence of Rpf/DSF signaling and, coupled with mutational studies, have allowed us to describe a number of new virulence factors for $X$. campestris pv. campestris.

\section{RESULTS}

Comparative proteomics of wild type and $r p f$ mutants.

Wild-type $X$. campestris pv. campestris 8004 and derived $r p f F$, $r p f G$, and $r p f C$ mutants were grown in nutrient yeast extract glycerol broth (NYGB) to an optical density at $600 \mathrm{~nm}$ $\left(\mathrm{OD}_{600}\right)$ of 0.8 . After harvesting by centrifugation, bacterial proteins were extracted and separated by two-dimensional (2D) electrophoresis as described below. A representative pair of gels is shown in Figure 1. Triplicate gels of each strain were 
compared. Approximately 300 to 400 protein spots were picked from two of these gels for each strain, and $>95 \%$ of these proteins were identified by matrix-assisted laser desorption-ionization time of flight (MALDI-TOF) analysis of tryptic peptides. Those proteins whose abundance at a single location in the gel differed significantly (present or absent) between the wild type, and different mutants are shown in Supplementary Table S1. Since multiple protein spots were picked and analyzed from each gel, it was evident that some proteins were found at different locations in the gels for the mutants as compared with the wild type. For the following analyses, these were considered to be as wild type. Some spots may move radically (Robin et al. 2013), so they might have evaded detection.

All of the 117 proteins with changes in abundance from the wild type in any mutant were categorized according to their functions, the biological processes in which they are involved, or both (Supplementary Fig. S1). Proteins involved in metabolism and regulation were most highly represented, but a range of other biological functions was seen, including motility and attachment, stress tolerance, transport, multidrug resistance, detoxification, signal transduction, and virulence.

The regulatory influence of individual Rpf proteins was then compared (Fig. 2). A number of proteins are seen to change in abundance compared with wild type in $r p f F, r p f C$, and $r p f G$ mutants. This finding is consistent with a linear signaling pathway whereby DSF is sensed by RpfC to activate RpfG. There appear to be additional complexities, however. For example, $\mathrm{RpfC}$ influences proteins that are not influenced by RpfG, and each of the Rpf proteins has a discrete regulatory action (Fig. 2 ). The results of this proteomic comparison thus support the conclusions of previous transcriptome-based analyses that the Rpf system in xanthomonads is a signal transduction 'hub' with additional inputs and outputs (Vorhölter 2013).

\section{Alteration in abundance of many proteins}

is not associated with alteration in transcript level.

The altered abundance of protein at one location in the $2 \mathrm{D}$ gel as a result of $r p f$ mutation could be due to transcriptional, post-transcriptional, or post-translational regulation to include modification or protein turnover. In an attempt to distinguish between these possibilities, the findings from proteomics were first compared with our previously reported comparative tran- scriptomic analysis of the different $r p f$ mutants and wild-type $X$. campestris pv. campestris grown under the same conditions (An et al. 2013). Surprisingly, there was little overlap between the genes with significantly altered levels of transcription (greater than fourfold) and proteins with altered levels of abundance. Only ten genes, $X C_{-}$0094, XC_0351, XC_0598, XC 0922, XC_2261, XC_2763, XC_2921, XC_2979, XC_3215, and $X C 3630$, showed both altered abundance of the encoded protein and altered transcript levels between mutants and wild type. The alteration in the level of transcript of these genes was confirmed by quantitative reverse-transcription-polymenrase chain reaction (qRT-PCR) (An et al. 2013).

Combined transcriptional-translational reporter fusions were constructed for a representative gene showing an altered level of transcription $\left(X C_{-} 2763\right)$ and three representatives $\left(X C_{-}\right.$ 0650, XC_2203, and $\left.X C \_2359\right)$ that showed no alteration in transcript level but an altered abundance of protein (Supplementary Table S2). These reporter fusions with gusA were constructed as described by $\mathrm{Lu}$ and colleagues (2012) (details below) and were introduced into the wild type and rpf mutants.
Reduced level in mutants

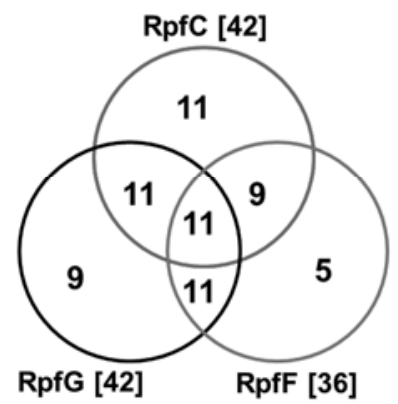

Increased level in mutants

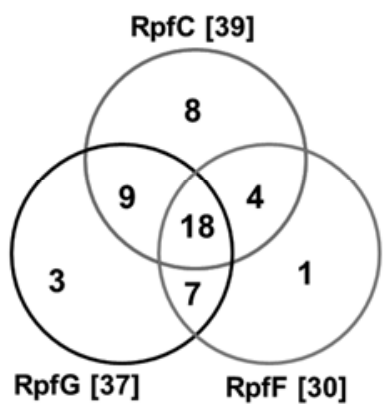

Fig 2. Venn diagram comparison of the regulatory influence of individual Rpf proteins. The numbers of proteins that are absent in the wild type and increase in the mutants is shown on the right, whereas those that are absent in the mutants but present in the wild type are shown on the left. Although a number of proteins are seen to change in abundance compared with wild type in all three $(r p f F, r p f C$, and $r p f G)$ mutants, consistent with a linear signaling pathway, the patterns of changes suggest that the Rpf/DSF system has additional complexities.
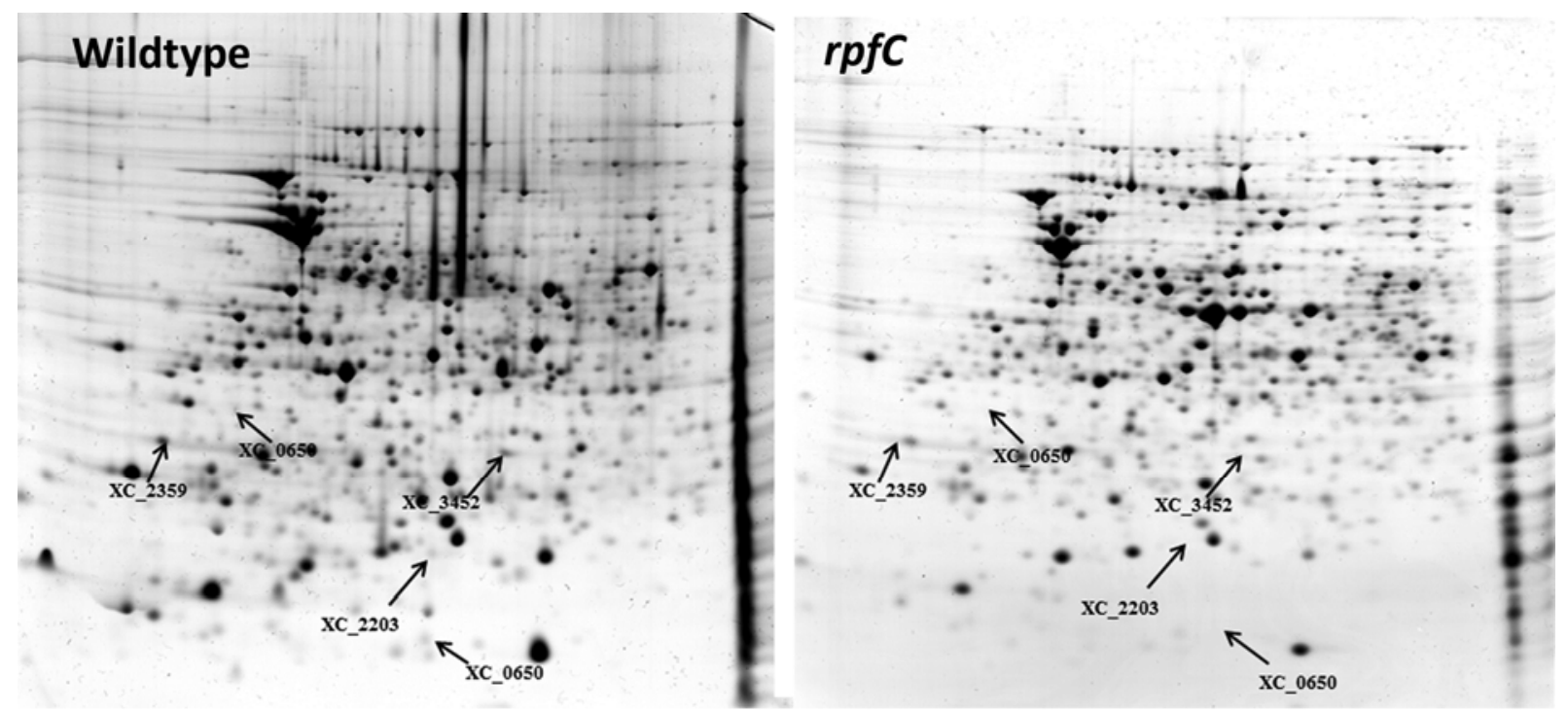

Fig. 1. Proteomic comparison of Xanthomonas campestris pv. campestris wild-type strain 8004 and rpfC mutant by two-dimensional-electrophoresis. Proteins were separated using isoelectric focusing in a gradient of $\mathrm{pH} 4$ (left) to $\mathrm{pH} 7$ (right), followed by sodium dodecyl sulfate-polyacrylamide gel electrophoresis. Gels were stained with Coomassie blue. The identity of several of the proteins present in the wild type but absent from the $r p f C$ mutant are indicated. Note that some of these appear at more than one position in the gels. 
As expected, the $\beta$-glucuronidase activity from constructs reporting $X C \_2763$ transcription-translation showed much lower activity in $r p f G, r p f C$, and $r p f F$ backgrounds compared with the wild type (Fig. 3). The $\beta$-glucuronidase activity from constructs reporting $X C \_0650$ was also lower in all three rpf backgrounds as compared with the wild-type, suggesting that expression of this protein is subject to post-transcriptional regulation. In contrast, $\beta$-glucuronidase activity from constructs reporting $X C_{-}$ 2203 and $X C_{2} 2359$ transcription-translation showed similar activity in the wild type and rpf mutants (Fig. 3). This suggests that the altered abundance of these proteins was due to post-

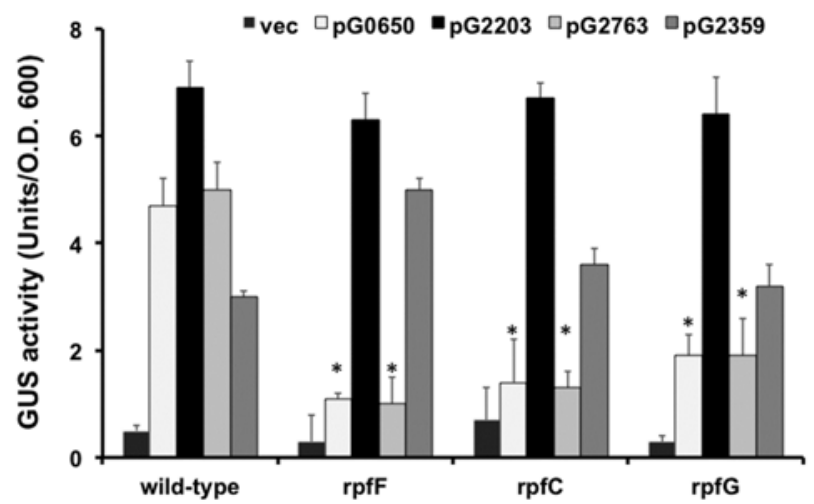

Fig 3. The activity of transcriptional-translational reporters for different genes in wild-type, $r p f G, r p f C$, and $r p f F$ backgrounds. Transcriptionaltranslational gusA reporter fusions for XC_2763, XC_0650, XC_2203, and $X C \_2359$ were assayed in wild type and different $r p f$ backgrounds. The $\beta$ glucuronidase (GUS) activity for the $X C \_2763$ and $X C \_0650$ reporters was reduced in the $r p f$ mutants. In contrast, the $X C \_2203$ and $X C \_2359$ reporters showed a similar level of GUS activity. The mean of duplicate measurements is shown. Asterisks indicate values that are significantly different from the appropriate wild-type $(P<0.05$, analysis of variance). translational modification or turnover. To distinguish these possibilities, constructs expressing XC_0650, XC_2203, and XC_2359 with C-terminal His6 tags were constructed, and the levels of the recombinant proteins in wild type and different $r p f$ backgrounds were assessed by Western analysis with an antiHis6 antibody. XC_0650, XC_2203, and XC_2359 were detected by Western analysis in the wild type but not in $r p f$ backgrounds (Supplementary Fig. S2). These findings are consistent with the contention that expression of XC_0650 is regulated at the post-transcriptional level. In contrast, the absence of $\mathrm{XC}_{-}$ 2203 and XC_2359 is indicative of post-translational turnover.

Taken together, these findings suggest that altered abundance of different proteins in rpf mutants can be due to transcriptional, post-transcriptional, or post-translational regulatory mechanisms. The further possibility that altered abundance of other proteins is due to post-translational modification causing movement to radically different locations on the gel should also not be overlooked (Robin et al. 2013).

\section{New factors that contribute to virulence among proteins with alteration in abundance.}

The contribution of proteins with altered abundance to the virulence of $X$. campestris pv. campestris was examined using mutagenesis. Mutants with single Tn5gusA insertions in genes of interest were identified within a library of such mutants (An et al. 2013; Ryan et al. 2007). Further mutants were constructed using derivatives of pK18 as outlined below. Virulence was tested by leaf clipping to introduce the bacteria into the vascular system of the test plant Chinese radish. This analysis revealed that 28 of the proteins identified by comparative proteomics contributed to the full virulence of $X$. campestris pv. campestris (Table 1). These proteins belong to a number of functional categories, including biosynthesis and intermediary metabolism, regulation, oxidative stress, or antibiotic resistance and DNA replication.

Table 1. The effects of mutation of genes encoding proteins influenced by the Rpf/DSF system on virulence ${ }^{a}$

\begin{tabular}{|c|c|c|c|c|}
\hline Locus tag & Predicted protein & Wild type & Alteration & Virulence \\
\hline XC_0481 & Anthranilate synthase component II & $\mathrm{P}$ & RpfF, RpfG, RpfC & I \\
\hline XC_0509 & Phosphoribosylamine-glycine ligase & $\mathrm{P}$ & RpfF, RpfG, RpfC & I \\
\hline XC_0979 & Fructose-bisphosphate aldolase & $\mathrm{P}$ & RpfF, RpfG & I \\
\hline XC_1876 & Argininosuccinate lyase & A & $\mathrm{RpfC}$ & I \\
\hline XC_2203 & Nucleotide diphosphate kinase & $\mathrm{P}$ & $\mathrm{RpfF}, \mathrm{RpfC}$ & I \\
\hline XC_0690 & Sugar kinase, adenosine kinase & $\mathrm{P}$ & RpfG & II \\
\hline XC_0281 & Oxidoreductase & $\mathrm{P}$ & $\mathrm{RpfF}$ & III \\
\hline XC_0450 & 4-Hydroxyphenylpyruvate deoxygenase & $\mathrm{P}$ & RpfF, RpfC & III \\
\hline XC_0650 & Hypothetical protein, outer membrane $\beta$-barrel & $\mathrm{P}$ & RpfF, RpfG, RpfC & III \\
\hline XC_0892 & Glutamate-1-semialdehyde aminotransferase & $\mathrm{P}$ & RpfG & III \\
\hline XC_1368 & Osmotically inducible protein, oxidative stress resistance & $\mathrm{P}$ & RpfG, RpfC & III \\
\hline XC_1510 & TldD protein, DNA gyrase control? & A & RpfF, RpfG, RpfC & III \\
\hline XC_2359 & Elongation factor $\mathrm{P}$ & $\mathrm{P}$ & RpfF, RpfG, RpfC & III \\
\hline XC_3287 & Phosphoglycerate mutase & $\mathrm{P}$ & RpfF, RpfG & III \\
\hline XC_3374 & Asparaginase & $\mathrm{P}$ & RpfC & III \\
\hline XC_3452 & Two-component regulatory protein & $\mathrm{P}$ & RpfG, RpfC & III \\
\hline XC_3615 & Electron transfer flavoprotein alpha subunit & $\mathrm{P}$ & RpfF & III \\
\hline $\mathrm{XC} \_0423$ & Maltooligosyltrehalose trehalohydrolase & $\mathrm{P}$ & RpfF, RpfC & IV \\
\hline XC_0501 & NADH pyrophosphatase & A & RpfF, RpfG, RpfC & IV \\
\hline XC_0537 & ATP-dependant DNA helicase & A & RpfG & IV \\
\hline XC_0570 & Iron utilisation protein & $\mathrm{P}$ & RpfF, RpfG, RpfC & IV \\
\hline XC_0630 & Hypothetical protein with AIM24 domain & A & RpfF & IV \\
\hline XC_0646 & Carboxyltransferase & A & RpfF, RpfG & IV \\
\hline XC__1182 & Glutathione synthetase & $\mathrm{P}$ & RpfC & IV \\
\hline XC_1481 & Beta-lactamase & A & RpfG, RpfC & IV \\
\hline XC_1565 & $\mathrm{N}$-5-glutamine S-adenosyl-L-methionine-dependent methyltransferase & A & RpfF, RpfC & IV \\
\hline XC_2162 & Hypothetical protein with peptidase M14 domain & A & $\mathrm{RpfF}, \mathrm{RpfC}$ & IV \\
\hline XC_2466 & Aspartate alpha-decarboxylase & A & RpfG, RpfC & IV \\
\hline
\end{tabular}

${ }^{a}$ The locus and predicted function of each protein is shown, whether it is present $(\mathrm{P})$ or absent $(\mathrm{A})$ in the wild type, and which Rpf proteins influence abundance. The virulence of each mutant was tested by measurement of the lesion length after bacteria were introduced into the vascular system of Chinese radish by leaf clipping. Mutants were assigned to classes I to $\mathrm{V}$ depending on the percentage lesion length when compared with the Xanthomonas campestris pv. campestris wild-type strain 8004 . $\mathrm{I}=0$ to $20 ; \mathrm{II}=21$ to $40 ; \mathrm{III}=41$ to $60 ; \mathrm{IV}=61$ to 80 ; and $\mathrm{V}=81$ to $100 \%$. 
The majority (17 of 28) of this panel of genes and proteins are involved in biosynthetic or catabolic pathways for amino acids, nucleotides, and carbohydrates or energy generation. It is likely that, for these genes, the effects of mutagenesis reflect the requirements for bacterial growth within the (limited) nutritional environment within the plant. Several of these genes are located in operons dedicated to specific pathways, indicating that transposon insertions are likely to have polar effects. These genes are $X C_{-} 0481$ (biosynthesis of aromatic amino acids), XC_0509 (purine metabolism), and $X C_{-} 1876$ (amino acid metabolism). For these cases, the phenotypes of independently derived mutants with transposon insertions in flanking genes were examined and were shown to have the same or similar influence on virulence, indicating the importance of the pathway as a whole for full virulence. Similarly, mutation of other genes in the XC_0421-XC_0428 operon, which is involved in glycogen metabolism, has a small effect on virulence as is seen with mutation of $X_{C} C_{-} 0423$.

A number of the mutations in other genes (specifically, XC_0450, XC0501, XC_0537, XC_0646, XC_0892, XC_1182, $X C_{-} 1565, X C_{-} 2203, X C_{-} 2466, X C_{-} 3287$, and $\left.X C_{-} 3615\right)$ potentially have polar effects, so that it is unclear whether they affect virulence per se. For example, $X C \_2203$ (encoding nucleotide diphosphate kinase) is the first gene in an operon with genes encoding proteins with unrelated or unknown function, including hypothetical proteins (XC_2202 and XC_2200) and

\section{A}

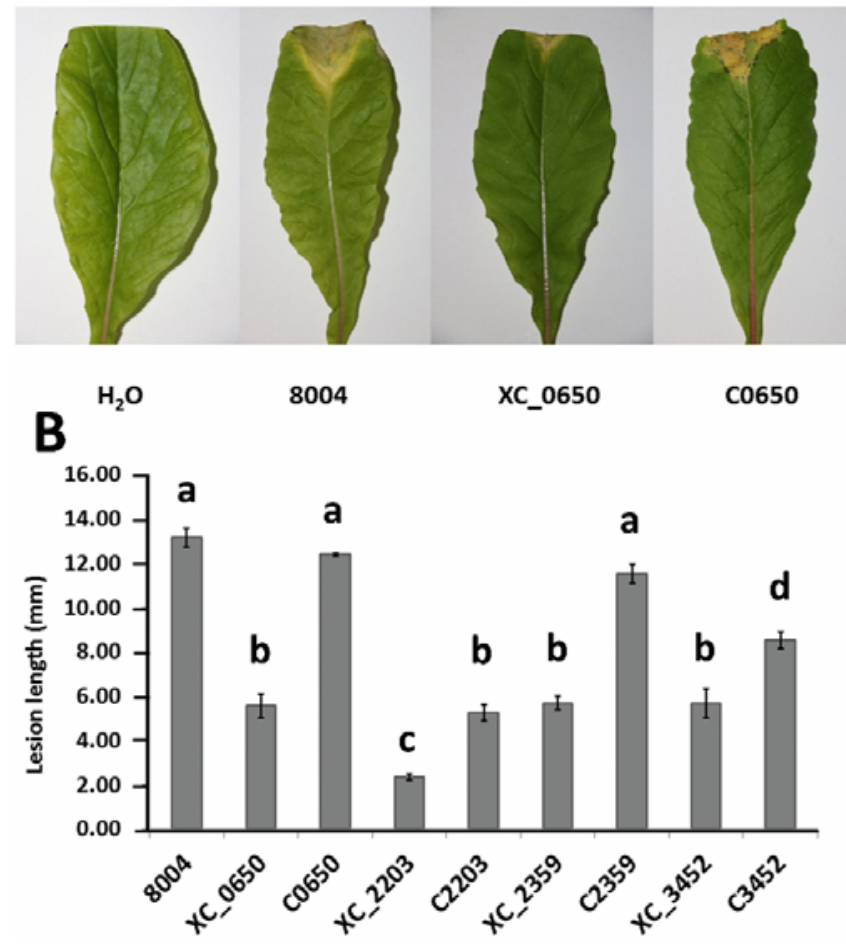

Fig. 4. Virulence of mutant and complemented Xanthomonas campestris pv. campestris strains in Chinese radish. The virulence of each strain was tested by measurement of the lesion length after bacteria were introduced into the vascular system of Chinese radish by leaf clipping. A, Comparison of symptoms in leaves inoculated with the $X C_{-} 0650$ mutant, complemented XC_0650 mutant (c0650), wild-type strain 8004, and control $\left(\mathrm{H}_{2} \mathrm{O}\right.$ inoculated). B, Virulence of $X C \_0650, X C_{-} 2203, X C \_2359$, and $X C_{-} 3452$ mutants and complemented mutants $\mathrm{cXC}$ _0650, cXC_2203, cXC_2359, and $\mathrm{c} X C_{-} 3452$ in comparison with wild-type strain 8004 . Up to 20 leaves were inoculated for each strain, and lesion length was measured 10 days after inoculation. The mean and standard deviation of these measurements are shown. Values with the same letter are not significantly different $(P<$ 0.05 , analysis of variance). a fimbrial biogenesis protein (XC_2201). In this case, mutation of these downstream genes had no effect on virulence. Furthermore, expression of XC_2203 alone could restore virulence of the $X C_{-} 2203$ mutant towards wild type (Fig. 4), suggesting the particular importance of this gene for virulence. Equally, transposon insertion in $X C_{-} 3614$ and $X C_{-} 3615$, which encode different subunits of the electron transfer flavoprotein complex, both affected virulence, but mutation of downstream genes in the predicted $X C \_3614-X C \_3620$ operon had no effect. In similar fashion, mutation of genes directly downstream of XC_0450, XC0537, XC_0892, XC_1182, and XC_3287 had no effect on virulence. In contrast, mutational analysis indicated a role in virulence for the transmembrane protein $\mathrm{AmpE}\left(\mathrm{XC}_{-}\right.$ 0502; virulence class IV), the sensor kinase XC_0647 (virulence class II), and hypothetical proteins XC_1566 and XC_2463 (both class IV).

The genes affecting virulence that are involved in regulation (4 of 28) include the two-component regulator XC_3452 and the translational elongation factor XC_2359. Complementation of the $X C \_2359$ mutant restored virulence to almost wild-type level (Fig. 4). Mutation of $X C_{-} 3451$, which encodes a twocomponent sensor and is located immediately downstream of $X C_{\_} 3452$ in the $X$. campestris pv. campestris genome, had the same effect on virulence as the mutation of $X C_{-}$3452. Complementation of the $X C_{-} 3542$ mutant restored virulence towards wild-type levels (Fig. 4).

Between the two genes of unknown function is $X C \_0650$, which is annotated as encoding a salt-induced outer membrane protein that is widely conserved in bacteria and comprises a DUF481 domain. $X C \_0650$ is a mono-cistronic gene and complementation of the $X C_{-} \_650$ mutant by in trans expression of the $X C \_0650$ gene restores virulence to wild-type (Fig. 4).

\section{DISCUSSION}

The work described here shows that mutation of genes involved in Rpf/DSF signaling has a substantial effect on the proteome of $X$. campestris pv. campestris, affecting proteins involved in a range of functions to include regulation, intermediary metabolism, stress tolerance, and motility. Likewise, a proteomic analysis of the regulatory function of DSF in $X$. oryzae pv. oryzicola revealed diverse regulatory effects on proteins involved in nitrogen transfer, protein folding, elimination of superoxide radicals, and flagellar formation (Zhao et al. 2011). The altered abundance of many of the proteins in $X$. campestris pv. campestris that we identified does not, apparently, involve alteration in gene transcription. The use of transcriptional-translation reporter fusions suggests that both posttranscriptional regulation and post-translational turnover can occur. These effects are not necessarily directly linked to alterations in the level of the second messenger cyclic di-GMP, which is associated with Rpf/DSF signaling, and could be the result of other (as yet undescribed) post-transcriptional regulatory events controlled by the Rpf/DSF system. Intriguingly, a recent proteomic analysis in $X$. oryzae pv. oryzae of the role of HrpX, which transcriptionally regulates synthesis of elements of the type III secretion apparatus and associated effectors, provided evidence that HrpX also controls post-translational modifications, such as glutamate methylation (Robin et al. 2013).

Mutation of a number of the genes encoding proteins with altered abundance has an effect on virulence. The relationship of these findings to the effects of rpf gene mutation on virulence should be interpreted cautiously. Some of these proteins may have undergone post-translational modification causing them to move to different positions in the gel. The nature of these modifications and their consequence for the activity of 
the proteins involved is not known; hence, it is not clear that loss by mutation mimics a physiological relevant effect of $\mathrm{Rpf} / \mathrm{DSF}$ signaling on protein activity. The situation is clearer for those proteins that are apparently absent from the different $r p f$ mutants, although different mechanisms may underlie this absence.

The majority of the proteins required for full virulence that we have described are involved in biosynthetic pathways for amino acids or nucleotides, catabolic pathways for carbohydrate degradation, or energy generation. Conventionally these proteins would not be considered virulence factors; their role would reflect the needs of the bacterium for growth in planta rather than in vitro. It is also perhaps not unexpected that proteins with known or suspected roles in resistance to oxidative stress (such as XC_1368 and the glutathione synthetase XC_1182) have a role in virulence.

Among the group of regulatory proteins that influence virulence are the two-component regulatory proteins XC_3452 and XC_2359, which is one of two elongation factor $\mathrm{P}$ proteins in $X$. campestris pv. campestris. The paralog of XC_2359 in X. campestris pv. campestris is $\mathrm{XC}_{-} 1843$, which is predicted to undergo post-translational modification by a beta-lysine substitution, leading to alterations in translation of specific proteins (Bailly and de Crécy-Lagard 2010; Navarre et al. 2010; Zou et al. 2011). The predicted site of modification of $X_{-}{ }_{-} 1843$ is a lysine residue that is absent in XC_2359. The homolog of XC_1843 in Salmonella spp. is known to be involved in the translation of a specific subset of proteins and to contribute to virulence (Navarre et al. 2010; Zou et al. 2011). In contrast, the influence of XC_2359 on protein translation patterns in $X$. campestris pv. campestris remains to be determined. Notably, homologs of XC_2359 are widely conserved in bacteria, but their role has not been analyzed. Homologs of the two-component regulator XC_3452 are also found in other xanthomonads, although mutagenesis of the homolog in a different strain of $X$. campestris pv. campestris has no effect on virulence in cabbage Brassica oleraceae cv. Zhonggan 8 (Qian et al. 2008).

Among the proteins of unknown function that regulate virulence is XC_0650, which is annotated as a salt-induced outer membrane protein and is widely conserved in bacteria. In silico predictions using Phyre2 (Kelley and Sternberg 2009) suggest that XC_0650 is a beta-barrel protein, structurally related to the outer membrane porin OmpG and a hemoglobin-binding protease autotransporter. The detailed role of XC_0650 in $X$. campestris pv. campestris is unknown, although it is conserved in xanthomonads as well as in unrelated bacterial genera.

It should be noted that our analysis is a 'snapshot,' taken at one growth point from bacteria growing in complex medium. The analysis of bacteria grown under different conditions may reveal a substantially different proteomic landscape. Nevertheless, the proteomic approach does provide new insights into the regulatory role of the Rpf/DSF system and intriguing leads for future study.

\section{MATERIALS AND METHODS}

\section{Bacterial strains and growth conditions.}

The wild-type $X$. campestris pv. campestris 8004 and derived $r p f F, r p f G$, and $r p f C$ strains have been described previously (Ryan et al. 2006; Slater et al. 2000). Mutants with single Tn5gusA insertions in further genes of interest were identified within a library of such mutants generated as described by An and associates (2013). The genomic positions of the transposon insertion within this library of mutants were established by thermal asymmetric interlaced PCR and sequencing for comparison with the full-genome sequence of $X$. campestris pv. campestris 8004 . Mutants were also created by the disrup- tion of genes with the use of the plasmid pK18mobkan, as described previously for $X$. campestris pv. campestris (An et al. 2013; Dow et al. 2003). An internal fragment of approximately $500 \mathrm{bp}$ of the gene to be disrupted was amplified by PCR, using $X$. campestris pv. campestris chromosomal DNA as template, and was cloned by using the TOPO TA cloning kit (Invitrogen, Carlsbad, CA, U.S.A.). The identity of the cloned fragment was confirmed by sequencing. The fragment was excised from this construct with EcoRI, which cuts at sites flanking the insert. This EcoRI fragment was ligated into pK18mobkan. This construct was conjugated from Escherichia coli DH5 $\alpha$ into $X$. campestris pv. campestris by triparental mating, using the helper plasmid pRK2073. Mutants were selected on plates containing rifampicin $(50 \mu \mathrm{g} / \mathrm{ml})$ and kanamycin $(12.5 \mu \mathrm{g} / \mathrm{ml})$. Mutants were screened for disruption of the selected gene by PCR.

All plasmids and strains used during this study are described in Suppementary Table S3. For all experiments, $X$. campestris pv. campestris strains were grown in NYGB medium (per liter, $5 \mathrm{~g}$ bacteriological peptone [Merck, Amsterdam, The Netherlands], $3 \mathrm{~g}$ yeast extract [Difco, Detroit], and $20 \mathrm{~g}$ glycerol) at $30^{\circ} \mathrm{C}$ with shaking. The antibiotics used were kanamycin, rifampicin, gentamycin, spectinomycin, and tetracycline at the indicated concentrations.

\section{Protein extraction.}

Bacterial culture $(200 \mathrm{ml})$ grown to an $\mathrm{OD}_{600}$ of 0.8 was centrifuged $\left(10 \mathrm{~min}, 3,000 \times \mathrm{g}, 4^{\circ} \mathrm{C}\right)$, and the pellet was resuspended in $20 \mathrm{ml}$ of wash buffer (50 mM Tris, $\mathrm{pH} 7.2)$ and was centrifuged again $\left(10 \mathrm{~min}, 3,000 \times g, 4^{\circ} \mathrm{C}\right)$. This wash step was repeated. Cells $(50 \mu \mathrm{g})$ were then resuspended in $650 \mu \mathrm{l}$ of disruption buffer (1 complete miniprotease inhibitor tablet [Roche Applied Science, Indianapolis, IN, U.S.A.] in $10 \mathrm{ml}$ $50 \mathrm{mM}$ Tris- $\mathrm{HCl}, \mathrm{pH} 7.4$ ) and were transferred into a $1.5-\mathrm{ml}$ reaction tube containing $800 \mu \mathrm{g}$ of glass beads. The cells were disrupted in a RiboLyser three times $\left(6.5 \mathrm{~m} \mathrm{~s}^{-1}, 20 \mathrm{~s}\right)$ and were placed on ice between ribolysing, until cooled. Samples were centrifuged $\left(30 \mathrm{~min}, 10,000 \times g, 4^{\circ} \mathrm{C}\right)$, and the supernatant was placed in a fresh tube (approximately 400 to $500 \mu \mathrm{l}$ ). Disruption buffer was added until the sample was $1 \mathrm{ml}$ and the sample was then centrifuged $\left(30 \mathrm{~min}, 10,000 \times g, 4^{\circ} \mathrm{C}\right)$ and the supernatant discarded. DTT $(28 \%$ dithiothreitol; $10 \mu \mathrm{l})$ was added to each sample before shaking (30 min, room temperature). Phenol $(650 \mu \mathrm{l})$ was then added to each sample, and the sample was shaken at room temperature for a further $30 \mathrm{~min}$ before centrifugation $(10 \mathrm{~min}, 10,000 \times g)$. The bottom layer was placed in a fresh tube and $15 \mu \mathrm{l}$ of DTT solution was added to each sample. $2 \mathrm{ml}$ of methanol/ammonium acetate solution were added to each sample before storage overnight at $-20^{\circ} \mathrm{C}$. Samples were centrifuged $\left(10 \mathrm{~min}, 3,000 \times g, 4^{\circ} \mathrm{C}\right)$ before washing the pellets several times with $70 \%$ ethanol. Pellets were then washed with $2 \mathrm{ml}$ of acetone and were left to dry for several hours. The dry pellet was then dissolved in $400 \mu \mathrm{l}$ of rehydration buffer ( $2 \%$ CHAPS in $8 \mathrm{M}$ urea). Protein concentrations were measured with the Bio-Rad Protein Assay (GE Healthcare, Piscataway, Nj, U.S.A.).

\section{D separation of proteins using gel electrophoresis.}

For separation in the first dimension, $450 \mu \mathrm{g}$ of protein was applied to the Bio-Rad immobilizing $\mathrm{pH}$ gradient (IPG) (pH 4 to 7) $18-\mathrm{cm}$ strip (GE Healthcare). All samples were adjusted to $350 \mu \mathrm{l}$ with rehydration buffer ( $2 \%$ CHAPS in $8 \mathrm{M}$ urea). A $28 \%$ solution of DTT $(2.5 \mu \mathrm{l})$ was then added, and samples were incubated at room temperature for $30 \mathrm{~min}$. Carrier ampholytes (pH 4 to 7, $2.5 \mu \mathrm{l}$; GE Healthcare) was added to the samples before centrifugation at $10,000 \times g$ for $5 \mathrm{~min}$. The protein solution was applied to the $\mathrm{pH} 4$ to 7 IPG strip for isoelectric 
focusing (IEF; Ettan IPGphor II IEF system; GE Healthcare), following the protocol of rehydration for $1 \mathrm{~h}, 30 \mathrm{~V}$ for $12 \mathrm{~h}$, $500 \mathrm{~V}$ for $1 \mathrm{~h}, 500$ to $1,000 \mathrm{~V}$ for $8 \mathrm{~h}, 1,000$ to $8,000 \mathrm{~V}$ for $3 \mathrm{~h}$, and steps of $8,000 \mathrm{~V}$ until $50,000 \mathrm{Vh}$. After IEF, strips were incubated in both equilibration buffer 1 (6 M urea, $2 \%$ sodium dodecyl sulfate [SDS], $50 \mathrm{mM}$ Tris, $\mathrm{pH} \mathrm{8.8,30 \%} \mathrm{glycerol,} \mathrm{2 \%}$ DTT) and in equilibration buffer 2 (6 M urea, 2\% SDS, 50 $\mathrm{mM}$ Tris [pH 8.8], 30\% glycerol, $2 \%$ iodacetamide) for 15 min. Separation in the second dimension was performed on a $10 \%$ polyacrylamide gel using a Bio-Rad PROTEAN II xi 2-D cell system, at $40 \mathrm{~mA}$ (per gel chamber) for approximately $16 \mathrm{~h}$. The gels were subsequently stained overnight using colloidal Coomassie blue.

\section{Image analysis.}

Following electrophoresis, gels were scanned using MagicScan and were analyzed with Delta2D software, using standard procedures and default parameters.

\section{In-gel tryptic digestion of proteins.}

Protein spots were excised using a GelPal from Genetix and were placed in a 96-well microtiter plate for tryptic digestion. The digest was performed according to the manufacturer's instructions (Promega, Mannheim, Germany). A saturated 4-hydroxy-3,5-dimethoxy-cinnamic acid matrix solution containing water, acetonitrile, and trifluoroacetic acid in a ratio 67:33:0.1 was added, in a 1:1 ratio, to the supernatant of the tryptic digestion.

\section{Mass spectrometry analysis.}

Each solution of digested proteins was pipetted onto an Anchor Chip steel target, and the corresponding peptide mass fingerprints were obtained from an Ultraflex MALDI-TOFmass spectrometer (Bruker, Bremen, Germany), using the standard manufacturer's parameters for peptide analysis. The Mascot search engine (Matrix Science, London) was used to identify proteins from a primary sequence database of $X$. campestris pv. campestris 8004 with the following parameters: trypsin as enzyme, up to two missed cleavages allowed, carbamidomethyl (C) Phospho (ST) and Phospho (Y) allowed as variable modification, a peptide tolerance of $125.0 \mathrm{ppm}$, and $\mathrm{ms} / \mathrm{ms}$ tolerance of $800.0 \mathrm{mmu}$. Only proteins with a Mowse score higher than 60 were considered as significant $(P<0.05)$.

\section{RNA extraction and preparation.}

Three independent cultures of each selected X. campestris pv. campestris strain were subcultured and were grown to an $\mathrm{OD}_{600}$ of 0.8 at $30^{\circ} \mathrm{C}$ in NYGB broth without selection. RNA protect ( $800 \mu \mathrm{l}$; Qiagen, Hilden, Germany) was added to 400 $\mu \mathrm{l}$ of culture and was incubated at room temperature for $5 \mathrm{~min}$. Cell suspensions were centrifuged, the supernatant was discarded, and pellets were stored at $-80^{\circ} \mathrm{C}$. After thawing, $100 \mu \mathrm{l}$ of TE-lysozyme $(400 \mu \mathrm{g} / \mathrm{ml})$ was added, and samples were incubated at room temperature. Total RNA was isolated using the RNeasy mini kit (Qiagen), whereby cells were homogenized utilizing a 20-gauge needle and syringe. Samples were treated with DNase (Ambion, Austin, TX, U.S.A.) according to manufacturer's instructions, and the removal of DNA contamination was confirmed by PCR.

\section{qRT-PCR.}

Reverse transcription was achieved using a cDNA synthesis kit (Promega) according to the manufacturer's instructions. RT-PCR was used to assess changes in transcript level for specific genes. Specific RT-PCR primers were used to amplify central fragments of approximately $200 \mathrm{bp}$ in length from different genes. For qRT-PCR, quantification of gene expression and melting curve analysis were completed, using an MJ Research PTC-200 Peltier Thermal Cycler and Platinum SYBR Green qPCR Supermix-UGD (Invitrogen) with 100 ng of template, according to manufacturer's instructions. The constitutively expressed housingkeeping gene $16 \mathrm{~S} r R N A$ was used as a reference to standardize all samples and replicates.

\section{DNA manipulation.}

Molecular biological methods such as isolation of plasmid and chromosomal DNA, PCR, plasmid transformation, as well as restriction digestion were carried out using standard protocols (Sambrook et al. 1989). PCR products were cleaned using the Qiaquick PCR purification kit (Qiagen), and DNA fragments were recovered from agarose gels using Qiaquick mini-elute gel purification kit (Qiagen). Oligonucleotide primers were purchased from Sigma-Genosys (The Woodlands, TX, U.S.A.).

\section{Construction of complementing clones.}

Complementing clones were constructed in pLAFR3, using DNA fragments amplified using primers detailed in Supplementary Table S4 as described previously (McCarthy et al. 2008).

\section{Construction of gusA reporter plasmids.}

Reporter plasmids pG0094, pG0650, pG2203, pG2359, pG2763, and pG3630 were constructed by cloning the putative promoter region and ribosome binding site (approximately 500-bp region upstream of the start codon) of $X C_{-} 0094, X C_{-}$ 0650, XC_2203, XC_2359, XC_2763, and XC_3630, respectively, into the broad-host-range cloning vector pL6gus, which harbors the coding region (without promoter and ribosome binding site) of the $\beta$-glucuronidase (gusA) gene in its multiple cloning site (Feng et al. 2009). The putative promoter region and ribosome binding site of $X C_{-}$0094, XC_0650, XC_2203, $X C \_2359, X C \_2763$, and $X C \_3630$ were amplified from the chromosomal DNA of $X$. campestris pv. campestris 8004 . The recombinant plasmid obtained was further confirmed by restriction analysis, PCR, and sequencing. All reporter plasmids were introduced into the $X$. campestris pv. campestris strains of interest through conjugation as previously described ( $\mathrm{Lu}$ et al. 2012).

\section{Construction of His6-tagged proteins for Western analysis.}

DNA fragments coding XC_0650, XC_2203, and XC_2359, including the putative promoter region (approximately 500-bp region upstream of the start codon), were amplified by PCR using $X$. campestris pv. campestris genomic DNA as template. The sequence of the reverse primer was altered to introduce 6His resides before the stop codon of each protein of interest and restriction sites to allow ease of cloning. After digestion with specific restriction enzymes, the PCR-amplified fragments were inserted into pLAFR6 as described previously (Ryan et al. 2006). All the plasmid constructs were confirmed by DNA sequencing. All constructs were introduced into the $X$. campestris pv. campestris strains of interest through conjugation as previously described (Lu et al. 2012).

\section{Virulence assays.}

The virulence of $X$. campestris pv. campestris to Chinese radish was estimated after bacteria were introduced into the leaves by leaf clipping as previously detailed (Dow et al. 2003; Ryan et al. 2007). Bacteria grown overnight in NYGB medium were washed and resuspended in water to an $\mathrm{OD}_{600}$ of 0.001 . For leaf clipping, the last completely expanded leaf was cut with scissors dipped in the bacterial suspensions. Up to 20 leaves were inoculated. Lesion length was measured 10 days after inoculation, and data were analyzed by Student's $t$ test. 


\section{ACKNOWLEDGMENTS}

The authors gratefully acknowledge support from grants awarded by the Science Foundation Ireland (SFI 07/IN.1/B955 to J. M. Dow and SFI 09/SIRG/B1654 to R. P. Ryan), the Society for General Microbiology (President's Fund for Research visit award to A. O'Connell) and by the Wellcome Trust (WT093314MA project grant to J. M. Dow and R. P. Ryan and WT100204AIA fellowship grant to R. P. Ryan).

\section{LITERATURE CITED}

An, S. Q., Febrer, M., McCarthy, Y., Tang, D. J., Clissold, L., Kaithakottil, G., Swarbreck, D., Tang, J. L., Rogers, J., Dow, J. M., and Ryan, R. P. 2013 High-resolution transcriptional analysis of the regulatory influence of cell-to-cell signalling reveals novel genes that contribute to Xanthomonas phytopathogenesis. Mol Microbiol. 88:1058-1069.

Bailly, M., and de Crécy-Lagard, V. 2010. Predicting the pathway involved in post-translational modification of elongation factor $\mathrm{P}$ in a subset of bacterial species. Biol Direct. 5:3.

Barber, C. E., Tang, J. L., Feng, J. X., Pan, M. Q., Wilson, T. J., Slater, H., Dow, J. M., Williams, P., and Daniels, M. J. 1997. A novel regulatory system required for pathogenicity of Xanthomonas campestris is mediated by a small diffusible signal molecule. Mol. Microbiol. 24:555-566

Chatterjee, S., Wistrom, C., and Lindow, S. E. 2008. A cell-cell signaling sensor is required for virulence and insect transmission of Xylella fastidiosa. Proc. Natl. Acad. Sci. U.S.A. 105:2670-2675.

Dow, J. M., Crossman, L., Findlay, K., He, Y.Q., Feng, J. X., and Tang, J. L. 2003. Biofilm dispersal in Xanthomonas campestris is controlled by cell-cell signaling and is required for full virulence to plants. Proc. Natl. Acad. Sci. U.S.A. 100:10995-11000.

Feng, J. X., Song, Z. Z., Duan, C. J., Zhao, S., Wu, Y. Q., Wang, C., Dow, J. M., and Tang, J. L. 2009. The xrvA gene of Xanthomonas oryzae pv. oryzae, encoding an H-NS-like protein, regulates virulence in rice. Microbiology 155:3033-3044.

Guo, Y., Zhang, Y., Li, J.-L., and Wang, N. 2012. Diffusible signal factormediated quorum sensing plays a central role in coordinating gene expression of Xanthomonas citri subsp. citri. Mol. Plant-Microbe Interact. 25:165-179.

He, Y. W., Xu, M., Lin, K., Ng, Y. J., Wen, C. M., Wang, L. H., Liu, Z. D., Zhang, H. B., Dong, Y. H., Dow, J. M., and Zhang, L. H. 2006. Genome scale analysis of diffusible signal factor regulon in Xanthomonas campestris pv. campestris: Identification of novel cell-cell communicationdependent genes and functions. Mol. Microbiol. 59:610-622.

Hengge, R. 2009. Principles of c-di-GMP signalling in bacteria. Nat. Rev. Microbiol. 7:263-273.

Kelley, L. A., and Sternberg, M. J. E. 2009. Protein structure prediction on the web: A case study using the Phyre server. Nat. Protoc. 4:363-371.

Lu, X. H., An, S. Q., Tang, D. J., McCarthy, Y., Tang, J. L., Dow, J. M., and Ryan, R. P. 2012. RsmA regulates biofilm formation in Xanthomonas campestris through a regulatory network involving cyclic di-GMP and the Clp transcription factor. PLoS One. 7:e52646. Published online.

McCarthy, Y., Ryan, R. P., O’Donovan, K., He, Y. Q., Jiang, B. L., Feng, J. X., Tang, J. L., and Dow, J. M. 2008. The role of PilZ domain proteins in the virulence of Xanthomonas campestris pv. campestris. Mol. Plant Pathol. 9:819-824.

Navarre, W. W., Zou, S. B., Roy, H., Xie, J. L., Savchenko, A., Singer, A., Edvokimova, E., Prost, L. R., Kumar, R., Ibba, M., and Fang, F. C. 2010. PoxA, YjeK, and elongation factor P coordinately modulate virulence and drug resistance in Salmonella enterica. Mol. Cell 39:209-221.

Qian, W., Han, Z.-J., Tao, J., and He, C. 2008. Genome-scale mutagenesis and phenotypic characterization of two-component signal transduction systems in Xanthomonas campestris pv. campestris ATCC 33913. Mol. Plant-Microbe Interact. 21:1128-1138.

Robin, G. P., Ortiz, E., Szurek, B., Brizard, J. P., and Koebnik, R. 2013. Comparative proteomics reveal new HrpX-regulated proteins of Xanthomonas oryzae pv. oryzae. J. Proteomics. Published online. doi:10.1016/j.jprot.2013.04.010

Römling, U., Galperin, M. Y., and Gomelsky, M. 2013. Cyclic di-GMP: The first 25 years of a universal bacterial second messenger. Microbiol. Mol. Biol. Rev. 77:1-52.

Ryan, R. P., and Dow, J. M. 2011. Communication with a growing family: Diffusible signal factor (DSF) signaling in bacteria. Trends Microbiol. 19:145-152.

Ryan, R..P., Fouhy, Y., Lucey, J..F., Crossman, L..C., Spiro, S., He, Y..W., Zhang, L..H., Heeb, S., Camara, M., Williams, P., and Dow, J. M. 2006. Cell-cell signaling in Xanthomonas campestris involves an HD-GYP domain protein that functions in cyclic di-GMP turnover. Proc. Natl. Acad. Sci. U.S.A. 103:6712-6717.

Ryan, R. P., Fouhy, Y., Lucey, J. F., Jiang, B.-L., He, Y.-Q., Feng, J.-X., Tang, J.-L., and Dow, J. M. 2007. Cyclic di-GMP signaling in the virulence and environmental adaptation of Xanthomonas campestris. Mol. Microbiol. 63:429-442.

Sambrook, J., Fritsch, E. F., and Maniatis, T. 1989. Molecular Cloning: A Laboratory Manual. 2nd ed. Cold Spring Harbor Laboratory Press, Cold Spring Harbor, NY, U.S.A..

Slater, H., Alvarez-Morales, A., Barber, C. E., Daniels, M. J., and Dow, J. M. 2000. A two-component system involving an HD-GYP domain protein links cell-cell signalling to pathogenicity gene expression in Xanthomonas campestris. Mol. Microbiol. 38:986-1003.

Von Bodman, S. B., Bauer, W. D., and Coplin, D. L. 2003. Quorum sensing in plant-pathogenic bacteria. Annu. Rev. Phytopathol. 41:455-482.

Vorhölter, F.-J. 2013. RNA-Seq facilitates a new perspective on signal transduction and gene regulation in important plant pathogens. Mol. Microbiol. 88:1041-1046.

Wang, N., Li, J. L., and Lindow, S. E. 2012. RpfF-dependent regulon of Xylella fastidiosa. Phytopathology 102:1045-1053.

Zhao, Y., Qian, G., Yin, F., Fan, J., Zhai, Z., Liu, C., Hu, B., and Liu, F. 2011. Proteomic analysis of the regulatory function of DSF-dependent quorum sensing in Xanthomonas oryzae pv. oryzicola. Microb. Pathogenesuis 50:48-55.

Zou, S. B., Roy, H., Ibba, M., and Navarre, W. W. 2011. Elongation factor $\mathrm{P}$ mediates a novel post-transcriptional regulatory pathway critical for bacterial virulence. Virulence 2:147-151.

\section{AUTHOR-RECOMMENDED INTERNET RESOURCE}

Delta2D software: www.decodon.com

This article was modified on March 16, 2017 


\section{ERRATUM / Volume 26, Number 10, 2013 / MPMI-05-13-0155-R}

In the article 'Proteomics Analysis of the Regulatory Role of Rpf/DSF Cell-to-Cell Signaling System in the Virulence of Xanthomonas campestris' by A. O'Connell, S.-Q. An, Y. McCarthy, F. Schulte, K. Niehaus, Y.-Q. He, J.-L. Tang, R. P. Ryan, and J. M. Dow, there was an error in Figure 4 panel A in which an incorrect set of images was inadvertently used to represent the virulence of the different strains. Although there was an error with these illustrative images, the quantitative data that is presented (derived from lesion length measurements of multiple leaves) is correct and fully supports the conclusions drawn. A corrected version of Figure 4 is given here. None of the conclusions of the paper are altered. We apologize to the readership of MPMI for this error and for any inconvenience caused.

\section{Revised Figure 4}

A

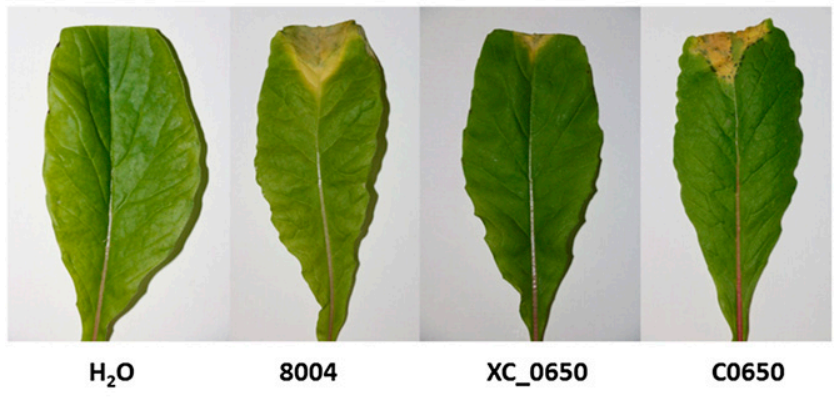

B

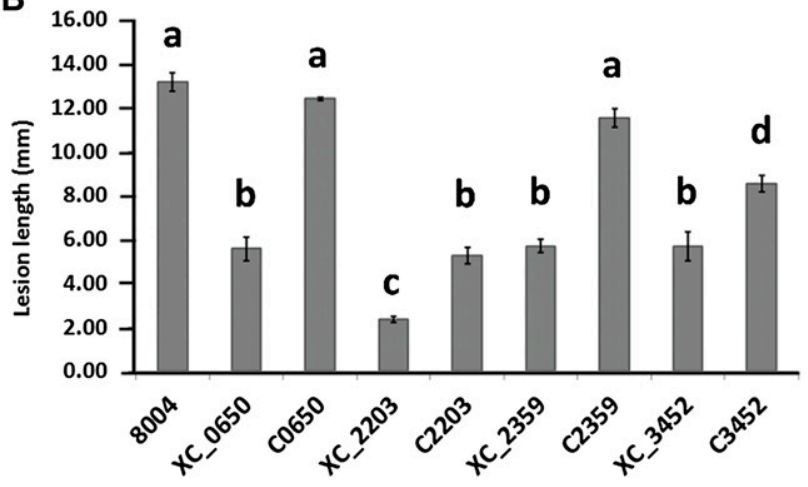

Fig. 4. Virulence of mutant and complemented Xanthomonas campestris pv. campestris strains in Chinese radish. The virulence of each strain was tested by measurement of the lesion length after bacteria were introduced into the vascular system of Chinese radish by leaf clipping. A, Comparison of symptoms in leaves inoculated with the $X C_{-} 0650$ mutant, complemented $X C \_0650$ mutant (c0650), wild-type strain 8004 , and control $\left(\mathrm{H}_{2} \mathrm{O}\right.$ inoculated). B, Virulence of $X C_{-} 0650, X C_{-} 2203, X C_{-} 2359$, and $X C_{-} 3452$ mutants and complemented mutants $\mathrm{c} X C_{\_} 0650, \mathrm{c} X C_{-} \_2203, \mathrm{c} X C_{-} \_2359$, and $\mathrm{c} X \mathrm{C}_{-} 3452$ in comparison with wild-type strain 8004. Up to 20 leaves were inoculated for each strain, and lesion length was measured 10 days after inoculation. The mean and standard deviation of these measurements are shown. Values with the same letter are not significantly different $(P<0.05$, analysis of variance).

\section{Previously Published Version}

A

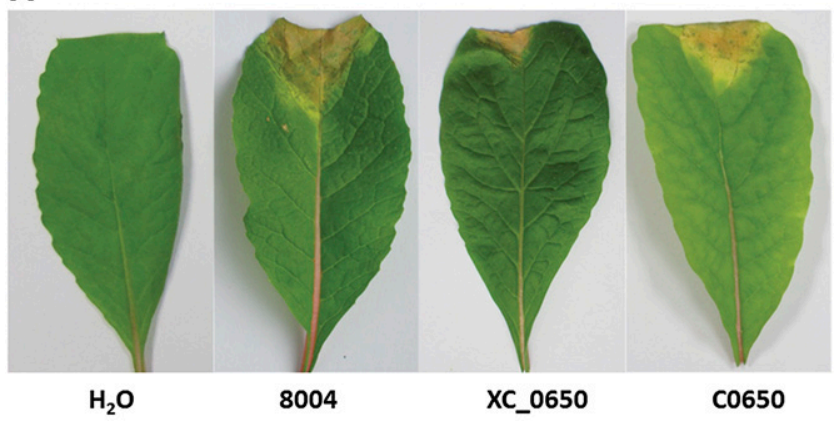

B

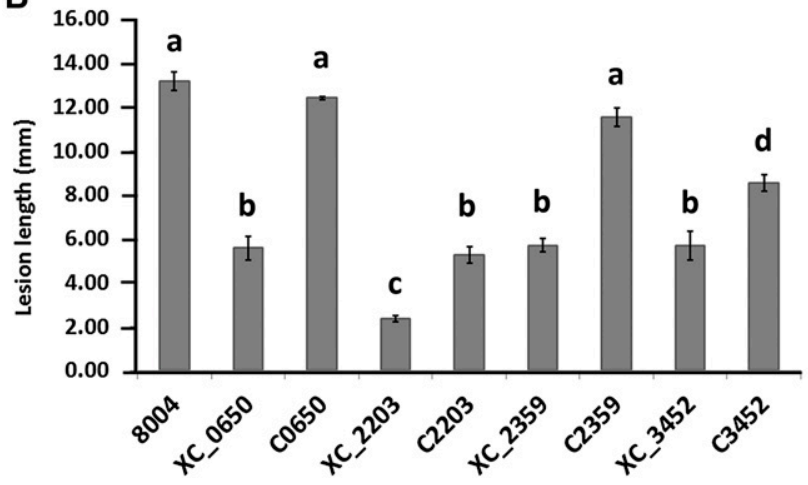

Fig. 4. Virulence of mutant and complemented Xanthomonas campestris pv. campestris strains in Chinese radish. The virulence of each strain was tested by measurement of the lesion length after bacteria were introduced into the vascular system of Chinese radish by leaf clipping. A, Comparison of symptoms in leaves inoculated with the XC_0650 mutant, complemented $X C \_0650$ mutant (c0650), wild-type strain 8004, and control $\left(\mathrm{H}_{2} \mathrm{O}\right.$ inoculated). B, Virulence of XC_0650, XC_2203, XC_2359, and XC_3452 mutants and complemented mutants cXC_0650, cXC_2203, cXC_2359, and cXC 3452 in comparison with wild-type strain 8004. Up to 20 leaves were inoculated for each strain, and lesion length was measured 10 days after inoculation. The mean and standard deviation of these measurements are shown. Values with the same letter are not significantly different $(P<0.05$, analysis of variance). 